\title{
Earthquake Impact Calculations of Kalinga Province Using Rapid Earthquake damage Assessment System (Redas) Software
}

\author{
Rafael J. Padre, Ronjohn R. Garming, Lope T. Buen \\ Faculty Members/Researchers, College of Engineering and Information Technology \\ Kalinga State University \\ Philippines \\ Robert A. Rodolfo \\ Director of Research and Development \\ Kalinga State University \\ Philippines
}

\begin{abstract}
This study was conducted to estimate earthquake risk in the province with the use of Rapid Earthquake Damage Assessment System (REDAS) software. There were three barangays from City of Tabuk, namely, Suyang, Casigayan and Dagupan Weste where actual building survey was taken to represent residential, commercial and mixed commercial and residential buildings of the province. These survey data were used in creating the database for Kalingafor the simulation and earthquake risk analysis in this study. Estimation of earthquake risk using REDAS was done based on 1949 historical earthquake event with a magnitude of 7.2 and a depth of $33 \mathrm{kms}$. Results showed that the total estimated floor area damages in square meters are 267,814, 227,344, 115,812, 339,995and 2751 for slight, moderate, extensive, complete with no collapse, and complete with collapse damages. Based on number of buildings, the total estimated damages under slight, moderate, extensive, complete with no collapse, and complete with collapse damages are 8948, 7290, 3620, 1044, and 75, respectively. The total estimated number of injuries across barangays of Kalinga is 641 minor injuries, 100 serious injuries, 5 very serious injuries and 21 fatalities with an estimated total economic loss of 2.602billion pesos. This study has demonstrated that REDAS is a valuable tool to estimate the extent of damages from a natural phenomenon like an earthquake. Information from the estimated extent of damages in particular areas of the province of Kalinga can guide those who are involved in disaster risk reduction planning and implementation.
\end{abstract}

Keywords: REDAS, earthquake risk, rapid assessment, inland active fault

\section{Introduction}

Disaster is a sudden calamitous event that seriously disrupts the functioning of a community or society and causes changes in the lives of affected individuals. Typhoons, earthquakes, floods, landslides, tsunamis and volcanic eruptions are natural disasters which are commonly experienced in the world. Sutanta et al., (2009) mentioned that in the last decade more than 500,000 people were the victim of various natural disasters all over the world. The economic damage in terms of absolute amount and percentage to GDP was also very high. The MMSU-REDAS research paper report said that, in the Philippines,more than $60 \%$ of the country's total land area is exposed to multiple hazards; and $74 \%$ of its population is at risk. Consequently, the weather-related disasters in the Philippines account for $90 \%$ of annual damages and cause on average of $0.7 \%$ losses to GDP growth.

The frequent occurrences of disasters in the country accompanied with an increasing trends of affected individuals had propelled the government to pass the RA 10121 otherwise known as the Philippine Disaster Risk Reduction and Management Act of 2010 and adopted a Strategic National Action Plan for Disaster Risk Reduction, effectively institutionalizing a comprehensive and integrated approach to risk reduction and management. According to the Philippine Institute of Volcanology and Seismology (PHIVOLCS) as cited by MMSU, the country experiences an average of twenty earthquakes a day and maybe attributed to its location in the Pacific Ring of fire where $90 \%$ of the world's volcanoes and a nearly continuous series of oceanic trenches and volcanic belts are situated, and plate movements occur. An earthquake is a term used to describe both sudden slip on a fault and the resulting ground shaking and radiated seismic energy caused by the slip, or by volcanic or magmatic activity, or other sudden stress changes in the earth. The location below the earth's surface where the earthquake starts is called the hypocenter, and the location directly above it on the surface of the earth is called the epicenter (http://earthquake.usgs.gov). 
The frequency of earthquake disaster is not as frequent as the typhoon and flooding that take place in the country. However, the impact generated on affected communities is usually massive and devastating. Earthquake-induced disasters were few in numbers in terms of casualties. PHIVOLCS revealed that within the 10 -year period five destructive earthquakes were recorded and human casualty included 15 deaths and 119 persons injured. Damage to the economy was estimated to reach P0.207-B. Also, the 1990 Luzon Earthquake, the Moro Gulf Tsunami and the collapse of the Ruby Tower were the most notably devastating earthquake disasters in the Philippines. The country is also prone to volcanic eruptions being situated along the Pacific Ring of Fire where two major tectonic plates (Philippine Sea and Eurasian) meet. This explains the occurrence of earthquakes and tsunamis and the existence of around 300 volcanoes of which 22 are active. Although earthquakes cannot be predicted, some studies show that 200 years is the return period for another major earthquake to occur in the same area.

In the Philippines, PHIVOLCS is mandated to provide timely and quality information and services for warning, disaster preparedness and mitigation. One of the strategies of PHIVOLCS to realize their mandate is the development of a simple and user-friendly simulation tool or software that can give a rapid estimate of the possible seismic hazards which can be used for inferring the severity of impacts to various elements-at-risk. This software is called "Rapid Earthquake Damage Assessment System" or REDAS. REDAS aims to provide quick and near real-time simulated earthquake hazard information to disaster managers which will help them in assessing the distribution and extent of the impacts of a strong earthquake. It is a decision support tool for spatial timely rescue and relief operations. The second objective is for the software to serve as a tool in convincing land use planners, policy makers, city and town development planners and even local government executives to consider earthquake hazards in their planning and development efforts so as to ensure long-term mitigation of seismic risks. Its' potential to be a risk assessment tool is being enhanced by improving the exposure database, inclusion of a building inventory module, incorporation of vulnerability curves and enhancing its modeling capability to address other natural hazards (www.phivolcs.dost.gov.ph).

Risk is the expected losses (of lives, persons injured, property damaged and economic activity disrupted) due to a particular hazard for a given area and reference period. The unit of measure could be the value of damaged property. Risk assessment includes the examination of risks resulting from natural events like flooding, extreme weather events, earthquakes, etc. that may pose threats to ecosystems, animals and people. It involves the process of quantifying and evaluating risk and their effects on economic activities and public services exposed to hazards in a given area. Quantitative risk assessment requires calculations of the magnitude of the potential loss, and the probability that the loss will occur. Quantified risk may be expressed as the number of elements lost, proportion of elements affected and monetary value of damaged property (http://www.neda.gov.ph/).

This study used REDAS to calculate the earthquakeimpactin the province of Kalinga.

\section{Objective}

The general objective of this study aimed to estimate earthquake risks using the RAPID Earthquake Damage Assessment System (REDAS) software.

Specifically, the study sought to:

a) developan earthquake exposure database for the province;

b) estimate risks and calculate loss due to earthquake; and

c) provide local executives and legislators a basis for policy formulation towards sound DRR/CCA initiatives.

\section{Review of Related Literature}

An earthquake cannot be predicted. However, on any particular fault, scientists know there will be another earthquake sometime in the future, but they have no way of telling when it will happen. The intensity of an earthquake is a number (written as a Roman numeral) describing the severity of an earthquake in terms of its effects on the earth's surface and on humans and their structures. Several scales exist, but the ones most commonly used in the United States are the Modified Mercalli scale and the Rossi-Forel scale. There are many intensities for an earthquake, depending on where you are. On the other hand, the magnitude is a number that characterizes the relative size of an earthquake. Magnitude is based on measurement of the maximum motion recorded by a seismograph. Several scales have been defined, but the most commonly used are (1)local magnitude (ML), commonly referred to as "Richter magnitude (http://earthquake. usgs.gov). In the Philippines, PHIVOLCS provides the Earthquake Intensity Scale. The greatest risk in an earthquake is the severity of the shaking; its causes to manmade and natural structures and the contents within these that may fail or fall and injure or kill people. There have been large earthquakes with very little damage because they caused little shaking and/or buildings were built to withstand that shaking. 
In other cases, smaller earthquakes have caused great shaking and/or buildings collapsed that were never designed or built to survive shaking. The buildings and their contents cause the death of people in the occurrence of earthquake (http://earthquake.usgs.gov).Recent and major events, as well as their cumulative impacts, highlight the importance of identifying the vulnerability levels of certain areas and segments of the Philippine population to collective hazards forming disasters. Vulnerability is defined as the susceptibility to stresses or hazards, and the capacity (or lack thereof) to prepare, cope and recover from such hazards. Human vulnerability, in particular, is a condition resulting from physical, social, economic and environmental factors, which determine the likelihood and scale of damage from the impact of a given hazard. Human vulnerability includes the vulnerability of social and economic systems, health status, physical infrastructure and environmental assets.

Vulnerability is the concept that explains why a community is more or less at risk to a given hazard. However, neither vulnerability alone nor hazard alone determines the occurrence of a disaster. A hazard, by itself, is simply a potentially damaging event or physical disturbance. It is in the coming together of hazard and vulnerability that disaster occurs (http://vm.observatory.ph).

After the July 16, 1990 earthquake that claimed many lives and destructions, PHIVOLCS-DOST team has developed Rapid Earthquake Damage Assessment System (REDAS) - a software which is intended to show near-real time scenario of an earthquake. It is an integrated system that considers building typologies, location, and some details of the earthquake event to come up with effects to immediate and nearby locations.

Republic Act (RA) No. 10121 otherwise known as the "Philippine Disaster Risk Reduction and Management Act of 2010" (PDRRM-2010) was enacted on May 27, 2010, to strengthen the Philippine disaster risk reduction system. It specifically provides for the development of policies and plans and the implementation of actions and measures pertaining to all aspects of disaster risk reduction and management, including good governance, risk assessment and early warning, knowledge building and awareness raising, reducing underlying risk factors, and preparedness for effective response and early recovery (COA, 2014).

There is really a need to protect both populations and properties against deaths, destructions and damages of properties. Hence, there should be immediate actions from planning, development, and proper implementation of policies and programs to mitigate the impact of earthquake. The United Nation and Development Program (UNDP, 2004) reported that natural disasters exert an enormous toll on development. In doing so, they pose a significant threat to prospects for achieving the Millennium Development Goals in particular, the overarching target of halving extreme poverty by 2015 . Annual economic losses associated with such disasters averaged US\$ 75.5 billion in the 1960s, US\$ 138.4 billion in the 1970s, US\$ 213.9 billion in the 1980s and US\$ 659.9 billion in the 1990s. The majority of these losses is concentrated in the developed world and fails to adequately capture the impact of the disaster on the poor who often bear the greatest cost in terms of lives and livelihoods, and rebuilding their shattered communities and infrastructure. UNDP further reported that, 85 percent of the people exposed to earthquakes, tropical cyclones, floods and droughts live in countries having either medium or low human development. The report shows that billions of people in more than 100 countries are periodically exposed to at least one event of earthquake, tropical cyclone, flood or drought. As a result of disasters triggered by these natural hazards, more than 184 deaths per day are recorded in different parts of the world. The UNDP report also demonstrates that development processes intervene in the translation of physical exposure into natural disaster events. The Report argues that disaster risk is not inevitable and offers examples of good practice in disaster risk reduction that can be built into ongoing development planning policy.

Sperling and Szekely (2005) cited that strategic coordination including the exchange of information, methodologies and tools between experts and institutions working on disaster risk management, climate change and development is essential for diminishing the impacts of natural disasters and improving the sustainability of development processes. Important synergies exist between the policy frameworks and practical methodologies for disaster risk management and the course recent scientific advances suggest will be required for adaptation to climate change. Many of the impacts associated with climate change exacerbate or alter existing threats (such as those associated with droughts, floods and extreme events), and adaptation measures can benefit from the practical experience in disaster management.

Heroldet al, (2005) recognized that successful disaster response strategies depend upon access to real-time spatial data/information that can be effectively utilized by not only relief agencies but also by local decision makers. They mentioned also that many local and regional authorities are developing geographic information system (GIS) - based spatial decision support systems (SDSS) in order to improve local disaster response and management capacity. Although such systems are useful, the evidence is that they tend to lack interoperability, and they require substantial GIS/technical knowledge through each of the design, development and implementation stages. Moreover, their creation and maintenance requires significant human and financial resources, and frequently access to information derived from such systems is very limited during the disaster response phase. 
Vulnerability assessment, which includes hazard analysis and risk assessment, allows the community to know how vulnerable they are and how hazards may affect them. Hazard mitigation, which includes measures to prevent hazards from causing emergencies or lessen their likely effects, protects the community from undue risks. Preparedness for disaster response, including planning and training, also contributes to prevent disasters by raising awareness to vulnerabilities and risks, thereby protecting the community and human development (De Guzman, undated).

GTZ 2004 as cited by Vlada and Nedelcu (2010) describe risks as always been part of daily life for humans and life without risk is neither possible nor conceivable. However, both the level of acceptance and the perception of risk vary from one individual to another. Perceptions also vary between regions, societies and cultures. For example, there are countries who support nuclear power plants without reservations, while others see the risk as to great. Furthermore, the authors also cited GTZ 2004 that there is no universally valid definition of risk, precisely because perceptions differ between individuals and cultures. In the context of disaster risk management, the following definition can be agreed: Risk is the probability of a harmful occurrence with a specific force at a specific location and a specific time. Risk relates to humans or objects at risk from natural events". Risk is something which has not happened yet, something which is projected into the future. If a risk is perceived as too high, there are two possibilities: eliminate the risk or reduce it as far as possible. How high the risk is judged to be, also depends on the available information about possible hazards. Adequate provision of information relating to hazards helps increase awareness and perception of risks. However, with growing poverty there are more and more situation in which the affected population accept the level of risks living near risk zones, and don't want to move away because it's possible to lose their job or other benefits.

Sutantaet al., (2009) mentioned that disaster has serious impact to our society in many aspects. In the last decade more than 500.000 people were the victim of various natural disasters all over the world. Economic damage in terms of absolute amount and percentage to GDP was also very high. The risk of some types of natural disasters, such as flood and landslide, can actually be reduced provided appropriate policies and infrastructures exist. According to Markus et al., (2004) that when urban areas are stricken by earthquake disasters and experience substantial destruction, in general the operable disaster response teams are overstrained. An efficient and integrated disaster management could support their activities and help to limit human losses. On the other hand, Barroca et. al., ( 2006) stated that risk consists of hazard and vulnerability. He further define "hazard" like "a threatening event, or the probability of occurrence of a potentially damaging phenomenon within a given time period and area". The (European Center of Technological Safety (2000) said that when a hazardous event ("hazard") occurs, the damage depends on the elements at risk. "Element at risk" is "the population, buildings and civil engineering works, economic activities, public services and infrastructure, etc. exposed to hazards".

\section{Historical and Recent Earthquake Events in Cordillera}

In the Cordillera Region, it was on July 16, 1990 that a killer earthquake unexpectedly hit and extensively devastated the City of Baguio. It was said to be the most destructive earthquake on record having a magnitude of 7.8 and lasted for 45 seconds. It was then that the REDAS was conceived and developed by PHIVOLCS in 2002-2004.In Kalinga Province, two major fault lines pass through a northeasterly direction from Mountain Province to Tinglayan- Mountain Mosimos-Lubuagan-Pasil-Balbalan. Another one passes through the same route from the corner boundary of Mountain Province and Abra to Tinglayan-Lubuagan and ends at Gobgob, Tabuk. So far, no records yet reflecting deadly earthquake ever hit Kalinga province

\section{Methodology}

\subsection{Capacity Building}

Before the start of the project activities, training on the use of the REDAS (Capacity Enhancement of Academic Researchers on Hazards, Risk Assessment and Exposure Database Development through the use of the REDAS software) was conducted at Currimao, Ilocos Norte administered by MMSU on May 2017. Enumerators were also briefed with proper techniques in the conduct of the actual survey of buildings to be used in the study. Another seminar on earthquake risk assessment in REDAS using survey data was conducted on December 4-9, 2017 at Mariano Marcos State University, Batac, Ilocos Norte.

\subsection{Site selection and survey proper}

Three barangays of Tabuk City, namely, Casigayan, Dagupan Weste and Suyang were the chosen barangays to gather building survey data that was used in the study. Tabuk City, Kalingais situated at 17.45 degrees North and 121.45 degrees east. It has an altitude of 200-500 feet above sea level. The town is drained by two major rivers (Chico River and Mallig River) and numerous tributaries, creeks and streams (See River Map). 
The western portion is characterized by interlinking mountain steep slopes, isolated flatlands, plateaus and valleys while the eastern portion consists of low lands and wide plains of rice fields. The said barangays were chosen and recommended by the TabukCity Disaster Risk Reduction Management Council (CDRRMC) to represent residential area, commercial area and combination of residential and commercial area. The EDM for android was used to gather the needed data which include among others the building use, structure, period built, geography, and estimated number of occupants. Prior to field immersion for the actual building survey, a permit from the local government unit was secured. Proper coordination with barangay officials was also done and relevant information about the barangay was obtained. Temporary identification cards (ID's) were issued to enumerators for proper identification.

\subsection{Brief Description of REDAS Software.}

The Philippine Institute of Volcanology and Seismology (PHIVOLCS) developed the Rapid Earthquake Damage Assessment System (REDAS) in 2002. REDAS is hazard simulation software that aims to produce hazard and risk maps immediately after the occurrence of a strong and potentially damaging earthquake with the following features:
a. It is a mapping software almost like a GIS.
b. It can produce deterministic ground shaking hazard maps for specific target areas.
c. It can produce liquefaction potential and landslide potential maps.
d. It can estimate tsunami heights, inundation and arrival times.
e. It can plot risk data (points, lines and polygons).
f. It does not require any other GIS software.
$\mathrm{g}$. It is a limited freeware but not an open source.

\subsection{Description of data collection using android}

Using the EDM for android, information about the different buildings which include among others building coordinates, building use, building type, building structure, period built, and estimated number of occupants was inputted in the database. The built-in camera for smart phone was also used to capture four (4) photos in each building which was used for the verification or correction of data. The sampled buildings were roughly $55 \%-95 \%$ in each class. The stored data in the EDM was transferred to MS Excel ${ }^{\circledR}$ daily, every after the survey. After transferring the data, significant time were allotted for the review of the survey data to ensure the highest possible quality assurance of the survey. This involved checking and correcting errors of the building location and other attributes that were gathered in the field. Some sources of the error in getting building coordinates are due to tall buildings, weather conditions or by the wrong estimation of the distance from the EDM user to the building. QGIS and Google Earth Pro were used to properly locate the building coordinates. QGIS software was used to convert Comma delimited (CSV) file into Keyhole Mark-up Language (KML) file so that it will be readily available for Google Earth. After the conversion, the KML file was opened in Google Earth Pro then the wrong points were relocated to their proper location by referring to the building information like horizontal plan shape and checking the building photos. Figure 2 shows a portion of surveyed data with the corrected building location.

\subsection{Actual Fieldwork, Problem Encountered and solutions}

During the survey, some of the house owners are afraid to be interviewed and disallow the enumerators to take pictures of their houses, especially so when barangay officials did not accompany the enumerators. Likewise, some of them were not around during their scheduled survey, pertinent information that needs to be answered in the questionnaire but were asked and obtained from their neighborhood.

\subsection{Survey data and Development of Exposure Database}

he EDM Software is a building exposure survey tool attached to REDAS for earthquake damage/impact assessment system to develop a building database for use in earthquake impact analysis. The survey tool can take photos of the buildings with its built-in camera and can determine the location through its built in Global Positioning System (GPS) and azimuth. It can also record the geography of the selected area, building attributes such as its use, number of occupants, structures, and the façade type of the establishment. Android phones equipped with android EDM application that contains the structured questionnaire were used. The required information for data analysis such as description, location and photos of the building were taken using the built-in camera, GPS and magnetic compass of the android device. After the survey, the data were cleaned and saved in the REDAS-EDM module.

From these building survey data, the exposure database for Tabuk City was developed and used in the seismic hazard assessment specifically for ground shaking using REDAS. Figures of the loss maps and graphs are developed for easy interpretation. 


\subsection{Types of barangays based on statistics}

The three (3) barangays of the province were classified according to building usage distribution; class 1 is residential (90\% residential and $10 \%$ commercial), mixed residential and commercial (60\% residential and $40 \%$ commercial) is under class 2 and class 3 is commercial (90\% commercial and 10\% residential). The classification was determined based on statistics.

\subsection{Earthquake Impact Calculation}

The 1949 magnitude 7.2 earthquake with a depth of 33 kilometers is one of the damaging earthquake in the region and was used for earthquake impact calculations of Kalinga province using REDAS Software. The damage/impact based on floor area, number of damaged buildings and the corresponding economic loss as well as the number of injuries and fatalities which are likely to occur were obtained using the REDAS software.

\section{Data Gathered}

There are 1,223 household surveyed from the three (3) representative barangays of Kalinga province, namely Casigayan, Dagupan Weste, and Suyang. Three (3) enumerators were hired and capacitated to facilitate the building survey. Coordination in the city local government unit as well as in the barangay offices was carried out before the conduct of enumeration. The data below were the results of the survey activities from the three pilot barangays in the province of Kalinga. The survey was performed by three enumerators in 14 working days (42 man-day).

\subsection{Building Statistics}

Structural type of a building is very important factor in calculating loss due to earthquake. The structural types considered in this study are the W1L (Wood, Light Frame), W3 (Bamboo), NL (Makeshift), CHBL ( Concrete Hollow Block), URAL (Unreinforced Adobe or Stone Bearing Walls), URML (Unreinforced Masonry Bearing Walls), MWSL (Concrete Hollow Blocks with Wood or Light Metal), CWSL (Reinforced Concrete Moment Frames with Wood or Light Metal), C1L (Concrete Moment Frames), C1M (Concrete Shear Walls), C4H (Concrete Shear Walls and Frames), PC2M (Precast Concrete Frames w/ Concrete Shear Walls), S1L (Steel Moment Frames),S3L (Light Metal Frames) and S4M (Steel Frames with Cast-in-Place Concrete Shear Walls). The Era of Construction for each building was tabulated to determine if the buildings are constructed conforming to the building codes. There were four (4) era of construction considered, the Pre-1972, 1972-1992, 1992-2010 and post 2010. There was no building code during Pre1972, 1972-1992 started the old building code and 1992-2010 marked the new building code where buildings can already bent when earthquake occur.

In all of the barangay surveyed, CHBL (Concrete Hollow Block) structural type dominates with a total number of 344 buildings, most number of buildings came from barangay DagupanWeste with a total of 288 buildings, followed by W1L with a total of 225 buildings and lastly C1L with a total of 196 buildings both still from barangay Dagupan Weste. On the other hand, C1M (Concrete Shear Walls) structural type was found only in barangay Casigayan and barangay Dagupan Weste as shown in Table 2. Overall barangay Dagupan Weste recorded the highest number of surveyed buildings with a total of 871 combining all the structural type. It is then followed by barangay Casigayan with 279 buildings and lastly barangay Suyang with a total of 73 buildings.

\section{2Number of Storey per Structural Type}

As shown in Table 1, one (1) storey building is dominating among the structural type registering 777 buildings out of 1223 buildings in the province, 344 buildings of CHBL (Concrete Hollow Block) recorded as the highest among the structural type followed by W1L (Wood, Light Frame) with a total of 312 buildings.

Table 1. Number of Storey's per structural type

\begin{tabular}{|l|l|l|l|l|l|l|}
\hline \multirow{2}{*}{ Structural Type } & \multicolumn{5}{|c|}{ Number of Storeys } & \multirow{2}{*}{ Grand Total } \\
\cline { 2 - 7 } & $\mathbf{1}$ & $\mathbf{2}$ & $\mathbf{3}$ & $\mathbf{4}$ & $\mathbf{5}$ & \\
\hline C1L & 99 & 167 & $\mathbf{0}$ & $\mathbf{0}$ & $\mathbf{0}$ & $\mathbf{2 6 6}$ \\
\hline C1M & 0 & 0 & $\mathbf{2 0}$ & $\mathbf{3}$ & $\mathbf{1}$ & $\mathbf{2 4}$ \\
\hline CHBL & 298 & 43 & $\mathbf{3}$ & $\mathbf{0}$ & $\mathbf{0}$ & $\mathbf{3 4 4}$ \\
\hline CWSL & 154 & 95 & $\mathbf{1}$ & $\mathbf{0}$ & $\mathbf{0}$ & $\mathbf{2 5 0}$ \\
\hline MWSL & 3 & 1 & $\mathbf{0}$ & $\mathbf{0}$ & $\mathbf{0}$ & $\mathbf{4}$ \\
\hline NL & 0 & 0 & $\mathbf{0}$ & $\mathbf{0}$ & $\mathbf{0}$ & $\mathbf{0}$ \\
\hline URML & 0 & 0 & $\mathbf{0}$ & $\mathbf{0}$ & $\mathbf{0}$ & $\mathbf{0}$ \\
\hline W1L & 202 & 110 & $\mathbf{0}$ & $\mathbf{0}$ & $\mathbf{0}$ & $\mathbf{3 1 2}$ \\
\hline W3L & 21 & 2 & $\mathbf{0}$ & $\mathbf{0}$ & $\mathbf{0}$ & $\mathbf{2 3}$ \\
\hline Grand Total & $\mathbf{7 7 7}$ & $\mathbf{4 1 8}$ & $\mathbf{2 4}$ & $\mathbf{3}$ & $\mathbf{1}$ & $\mathbf{1 2 2 3}$ \\
\hline
\end{tabular}




\subsection{Era of Construction per Structural Type}

The most dominant era of construction in the province is 1992-2010. New building code is already effective during this era. The Pre-1972 era of construction had the least number of building constructed as shown in Table 2.

Table 2. Era of construction per structural type

\begin{tabular}{|l|l|l|l|l|l|}
\hline \multirow{2}{*}{ Structural Type } & Era of Construction & \multicolumn{2}{l|}{ Grand } \\
\cline { 2 - 6 } & $\mathbf{2 0 1 0}$ & $\begin{array}{l}\mathbf{1 9 7 2 -} \\
\mathbf{1 9 9 2}\end{array}$ & $\mathbf{1 9 9 2 - 2 0 1 0}$ & $\begin{array}{l}\text { Pre } \\
\mathbf{1 9 7 2}\end{array}$ & \begin{tabular}{l} 
Total \\
\hline C1L
\end{tabular} \\
\hline C1M & 86 & 34 & 140 & 6 & $\mathbf{2 6 6}$ \\
\hline CHBL & 11 & 1 & 12 & 0 & $\mathbf{2 4}$ \\
\hline CWSL & 41 & 130 & 168 & 5 & $\mathbf{3 4 4}$ \\
\hline MWSL & 37 & 53 & 133 & 27 & $\mathbf{2 5 0}$ \\
\hline NL & 1 & 0 & 3 & 0 & $\mathbf{4}$ \\
\hline URML & 0 & 0 & 0 & 0 & $\mathbf{0}$ \\
\hline W1L & 0 & 0 & 0 & 0 & $\mathbf{0}$ \\
\hline W3L & 29 & 76 & 183 & 24 & $\mathbf{3 1 2}$ \\
\hline Grand Total & 0 & 10 & 11 & 2 & $\mathbf{2 3}$ \\
\hline
\end{tabular}

\subsection{Floor Area per Structural Type}

In terms of floor area per structural types, C1L (Concrete Moment Frames) dominates among the structures with 85,256.25 square meters of the total buildings surveyed followed by 53,156.25 square meters of CHB (Concrete Hollow Block). The MWSL (Half-Masonry) recorded the least structural type in terms of floor area with 931.25 square meters.

\section{Discussion of Results}

\subsection{Earthquake Parameters and Risk Estimation}

The 1949 magnitude 7.2 earthquake is one of the damaging earthquake in the region and was used for risk and loss estimation using REDAS Software in the province with a depth of 33 kilometers. The possible damage based on floor area, number of damaged buildings and the corresponding economic loss as well as the number of casualties was determined.

\subsection{Damages and Losses}

From the impact estimation using the REDAS software, the possible damage based on floor area and number of damaged buildings, the corresponding economic loss as well as the number of casualties brought about by a 7.2 magnitude earthquake were determined. The projected physical damages in Kalinga due to magnitude 7.2 earthquake are shown in Table 3. Based on floor area about $647,716.13 \mathrm{~m}^{2}$ will be affected. Likewise, a total of 20977 buildings will be affected, most of which will have slight damage (8948) to moderate damage (7290). It is projected that a total of 75 buildings will have complete damage with collapse using the REDAS software simulation. Table $4 \& 5$ shows the summary of damages in terms of floor area and building damages in each of the municipalities of Kalinga. For the projected economic loss due to the 7.2 magnitude earthquake. The province will experience an estimated economic loss of 1.745 billion pesos, of which 1.393 million were concentrated in the City of Tabuk. Tabuk City was located and near the epicenter along the fault line and trench. On the other hand, the estimated number of casualties, 641 for minor injuries, 100 for serious injuries and 5 for very serious injuries. Most of the death toll (21) come from the City of Tabuk(Table 6).

Table 3. Projected physical damage in Kalinga due to M7.2 Earthquake

\begin{tabular}{|l|l|l|}
\hline Damage & Floor Area $\left(\boldsymbol{m}^{2}\right)$ & No. of Buildings \\
\hline Slight Damage & 267,814 & 8948 \\
\hline Moderate Damage & 227,344 & 7290 \\
\hline Extensive Damage & 115,812 & 3620 \\
\hline Complete Damage with no Collapse & 33,995 & 1044 \\
\hline Complete Damage with Collapse & 2,751 & 75 \\
\hline Total Damage & 647,716 & 20977 \\
\hline
\end{tabular}


Table 4 . Projected Floor area damages in Kalinga due to M7.2 earthquake

\begin{tabular}{|l|l|l|l|l|l|l|}
\hline Municipality & $\begin{array}{l}\text { Slight } \\
\text { Damage }\end{array}$ & $\begin{array}{l}\text { Moderate } \\
\text { Damage }\end{array}$ & $\begin{array}{l}\text { Extensive } \\
\text { Damage }\end{array}$ & $\begin{array}{l}\text { Complete } \\
\text { Damage }\end{array}$ & $\begin{array}{l}\text { Complete } \\
\text { Damage w/ } \\
\text { Collapse }\end{array}$ & $\begin{array}{l}\text { Total } \\
\text { Floor } \\
\text { Area }\end{array}$ \\
\hline Balbalan & 5546.416 & 2001.301 & 435.371 & 49.862 & 4.806 & 61003 \\
\hline Lubuaga & 3203.756 & 1038.952 & 212.259 & 22.704 & 2.248 & 45674 \\
\hline Pasil & 3651.308 & 1248.166 & 264.789 & 29.753 & 2.892 & 45499 \\
\hline Pinukpukan & 24309.19 & 17242.84 & 7165.572 & 1684.947 & 139.582 & 141568 \\
\hline Rizal & 20404.11 & 18309.37 & 9543.351 & 2824.137 & 232.243 & 105427 \\
\hline Tabuk City & 204438.6 & 184749.4 & 97400.56 & 29253.97 & 2358.274 & 881248 \\
\hline Tanudan & 4123.71 & 2172.958 & 684.157 & 119.812 & 10.259 & 31908 \\
\hline Tinglayan & 2137.167 & 580.698 & 105.83 & 9.856 & 1.037 & 41634 \\
\hline
\end{tabular}

Table 5. Projected building damages in Kalinga due to M7.2 earthquake

\begin{tabular}{|c|c|c|c|c|c|c|}
\hline & $\begin{array}{l}\text { Slight } \\
\text { Damage }\end{array}$ & $\begin{array}{l}\text { Moderate } \\
\text { Damage }\end{array}$ & $\begin{array}{l}\text { Extensive } \\
\text { Damage }\end{array}$ & $\begin{array}{l}\text { Complete } \\
\text { Damage }\end{array}$ & $\begin{array}{ll}\text { Complete } & \\
\text { Damage } & \text { w/ } \\
\text { Collapse }\end{array}$ & $\begin{array}{l}\text { Total } \\
\text { Building }\end{array}$ \\
\hline Balbalan & 260 & 97 & 21 & 1 & 0 & 379 \\
\hline Lubuaga & 174 & 56 & 11 & 0 & 0 & 241 \\
\hline Pasil & 176 & 57 & 12 & 0 & 0 & 245 \\
\hline Pinukpukan & 1244 & 898 & 378 & 92 & 3 & 2615 \\
\hline Rizal & 834 & 743 & 383 & 112 & 9 & 2081 \\
\hline Tabuk City & 5883 & 5293 & 2780 & 835 & 63 & 14854 \\
\hline Tanudan & 217 & 101 & 29 & 4 & 0 & 351 \\
\hline Tinglayan & 160 & 45 & 6 & 0 & 0 & 211 \\
\hline TOTAL & 8948 & 7290 & 3620 & 1044 & 75 & 20977 \\
\hline
\end{tabular}

Table 6. Projected casualties in Kalinga due to M7.2 earthquake

\begin{tabular}{|l|l|l|l|l|l|}
\hline & Minor Injury & Serious Injury & Very Serious Injury & Fatalities & TOTAL \\
\hline Pinukpuk & 77 & 7 & 0 & 1 & 85 \\
\hline Rizal & 73 & 9 & 0 & 0 & 82 \\
\hline Tabuk & 487 & 84 & 5 & 20 & 596 \\
\hline Tannudan & 4 & 0 & 0 & 0 & 4 \\
\hline TOTAL & 641 & 100 & 5 & 21 & 767 \\
\hline
\end{tabular}

\section{Conclusion and Recommendations}

The survey was conducted in three selected barangays as representative of commercial, residential, and mixed commercial-residential areas. Out of the 1223 buildings, majority of the buildings surveyed in the study sites are of CHBLL-type (28.13\%), followed by W1L (25.51\%), C1L (21.75\%), CWSL (20.44\%), C1M (1.90\%), W3L (1.88\%) andMWSL (.0.03\%). On the other hand, 53.15\% (650)of the buildings were built between1992 and 2010, $16.76 \%$ (205)were built after 2010, 24.86\% (205) were built between 1972 and 1992, and $5.23 \%$ (64) were built before 1972.

The simulation of earthquake impact calculations were based on the magnitude 7.2 earthquake with depth of 33 kilometer that occurred in Kalinga on December 29, 1949. Hazard maps were generated and impact was estimated using the seismic hazard assessment of the REDAS software. Based from the simulation results, the province will experience slight to complete damage with collapse. A total damage from slight damages to complete damages with collapse is $378,832.25 \mathrm{~m}^{2 \text { for }}$ floor area and 12,029 buildings will be affected and damaged from slight to complete damages with collapse. These values are based on impact estimation and ground-shaking simulations only excluding the effects of possible landslides, liquefaction, and/or tsunami. An economic loss of 2.6billion pesos is likewise estimated. The earthquake also leaves casualties which include 641 slight to serious injuries and100 minor injuries. Based from the simulation of the magnitude 7.2 earthquakes, it left 21 people dead and 5 serious injuries.

With this projected impact statistics, the provincial government should be more active in the implementation of DRR activities.Like any other software, REDAS has been proven as a valuable tool in vulnerability mapping and risk estimation. Ground shaking and other hazard maps can be generated. Moreover, impact estimation in terms of building and floor damage, economic loss, and number of casualties can also be estimated. Hence, the results of the study can already serve as bases for policy formulation to reduce earthquake risks. 


\section{Sponsoring information:}

1. Mariano Marcos State University (MMSU), City of Batac, Ilocos Norte, Philippines.

2. Department of Science and Technology-Philipppine Institute of Volcanology and Seismology

\section{Acknowledgments}

The authors would like to express their heartfelt gratitude to the KSU President- Dr. Eduardo T. Bagtang for allowing his faculty to work in this project, to MMSU, DOST- PHIVOLCS, DOST-PCIEERRD and ISU, for the technical and financial assistance, the Tabuk City Government for providing them the data needed in the conduct of this project.

\section{Literature Cited}

ALBERT M.G. KLEIN TANK, ROYAL NETHERLANDS METEOROLOGICAL

INSTITUTE, FRANCIS W. ZWIERS and XUEBIN ZHANG 2009. Guidelines on Analysis of extremes in a changing climate in support of informed decisions for adaptation.

ASSILZADEHA H. and MANSORA S.B. (Undated). Natural Disaster Data and Information Management System

Center for Environmental Geomatics-Manila Observatory. 2005. Mapping Philippine Vulnerability to Environmental Disasters. http://vm.observatory.ph/geophys_maps.html.

Commission on Audit. 2014. Assessment of Disaster Risk Reduction and Management (DRRM) at the Local Level

FIORUCCI P., GAETANI F., MINCIARDI R. and TRANSFORINI E. 2005. Natural risk assessment and decision planning for disaster mitigation. Advances in Geosciences, 2, 161-165, SRef-ID: 1680-7359/adgeo/2005-2-161 European Geosciences Union

GEHBAUER F. MARKUS M. ENGELMANN H. POPAZ I., SCHWEIER C, REHORA

Mand WERDER S. 2007.The Disaster Management Tool.InternationalSymposium on Strong Vrancea Earthquakes and Risk Mitigation, Bucharest, Romania.

MITCHELL T., AND MAARTEN V.A. 2008.Convergence of Disaster Risk Reduction and Climate Change Adaptation.A review for Department for International Development

MARKUSI M., FIEDRICH F., LEEBBMANN J., SCHWEIER C., AND

STEINLE E. 2004. Concept for an Integrated Disaster Management Tool.13 ${ }^{\text {th }}$ World Conference on Earthquake Engineering.

REINHARD MECHLER 2005. Cost-benefit Analysis of Natural Disaster Risk Management in Developing Countries. Manual "Disaster Risk Management in Development Cooperation"

SUTANA H., RAJABIFARD A., AND BISHOP I.D. (2009). An Integrated Approach for Disaster Risk Reduction UsingSpatial Planning and SDI Platform. In: Ostendorf B., Baldock, P., Bruce, D., Burdett, M. and P. Corcoran (eds.), Proceedings of the Surveying \& Spatial Sciences Institute Biennial International Conference, Adelaide 2009, Surveying \& Spatial Sciences Institute, pp. 341-351. ISBN: 978-0-9581366-8-6.

TORRES, RONNIE C., PALADIO, MA. LYNN, PUNONGBAYAN, RAYMUNDO, ALONSO, ROSALITO. 1990. Mapping of Areas Affected by Liquefaction during the 16 July 1990 Earthquake.

UNDP 2004.Reducing Disaster Risk: A Challenge for Development. New York :United Nations, ISBN 92-1-126160-0 Printed by John S. Swift Co., USA

VLAD M.I. and NEDELCU I. Assessing the Flood Risk in Urban Environment Using Disaster Risk Management Specific Indicators.

YELETAYZI S., OZCEYLAN D., and FIEDRICH FRANK 2009. A Framework to

Integrate Social Vulnerability into Catastrophic Natural Disaster Preparedness

Planning. Proceedings of Annual Conference Istanbul.

Philippine Institute of Volcanology and Seismology- Department of Science \& Technologyhttp://www. phivolcs. dost.gov .ph/html/update_SOEPD/1990LuzonEQ_Monograph/foreword.html.

World Conference on Disaster Reduction. January 2005. Hyogo Framework for Action: Building the Resilience of Nations and Communities to Disasters. Retrieved October 2014 at

http://www.unisdr.org/2005/wcdr/intergover/official-doc/L-docs/Hyogo-framework-for-action-english.pdf.

REDAS Manual 